\title{
PRE-LABOUR RUPTURE OF MEMBRANES AT TERM;
}

\section{COMPARISON OF EXPECTANT MANAGEMENT AND INDUCTION OF LABOUR USING MISOPROSTOL (PGE1)}

Dr. Bushra Khan, Dr. Nuzhat Rasheed, Dr. Bushra Mukhtar.

ABSTRACT... Objective: To compare maternal and perinatal outcome in cases of PROM at term, following induction with vaginal misoprostol (PGE1) to shorten the duration of labour with those managed expectantly. Design: Quasi Experimental study. Setting: The study was carried out in department of obstetrics and gynecology labour room unit-1, Bahawal Victoria Hospital, Bahawalpur. Population: Term pregnancies (37-42 wks) with PROM and cephalic alive fetuses. Methods: Sixty patients with confirmed diagnosis of PROM were randomized into two groups i.e, A\&B. Group A comprising 30 patients were induced with tab. Misoprostol 25 ug at 6 hrly interval max of four doses and group B was managed expectantly for $24 \mathrm{hrs}$ followed by induction with intravenous oxytocin. Outcome Measures: Total duration of labour, mode of delivery, maternal infection rates and, APGAR score at 1 and 5 min. Results: It was found that both groups had similar characteristics, but the misoprostol group had a significantly shorter time interval from PROM to delivery (18.9 vs 27.5 hours) i.e total duration of labour. Caesarean section rates were $20 \%$ in the misoprostol group and $30.7 \%$ in the other. There were no differences between them regarding fetal well being, complications during labour and delivery and neonatal or postpartum maternal morbidity. Within 24 hours, $44 \%$ of women had delivered in the expectant group against $73.3 \%$ in the misoprostol group. Conclusion: Immediate labour induction with misoprostol in cases of term PROM shortens the total duration of labour, and the time of maternal hospitalization without any maternal and perinatal outcomes disadvantages.

Key words: PROM, intraamniotic infection, misoprostol.

Article Citation

Khan B, Rasheed N, Mukhtar B. Pre-labour rupture of membranes at term; comparison of expectant management and induction of labour using misoprostol (PGE1). Professional Med J 2013;20(5): 731-735.

\section{INTRODUCTION}

Per-labour rupture of membranes (PROM) at term is rupture of membranes prior to the onset of labour at or beyond 37 weeks gestation'.

PROM occurs in approximately $5-10 \%$ of all pregnancies of which about $60 \%$ occur at term ${ }^{2,3} .80 \%$ of patients with PROM at term go into spontaneous labour within 24 hours ${ }^{4}$. PROM carries both maternal and fetal risks. In PROM, 25\% cases are complicated with infection i.e, chorioamnionitis. Postnatal sepsis occurs in $10 \%$ cases, although serious maternal infection is rare upto $1-2 \%$.

Fetal risks include neonatal sepsis which occurs in 2$4 \%$ cases $^{5}$. Fetal hypoxia is also more likely to occur due to greater chance of cord prolapse, cord compression and abruption placenta associated with PROM. Neonatal morbidity is increased because of mechanical difficulty in delivery, increased chance of malpresentation and decreased amount of liquor ${ }^{6}$.
PROM at term is managed either expectantly or by Induction. Expectant management consists of hospitalization and continued clinical observation of mother and fetus ${ }^{7}$. Induction is stimulation of uterus with the aim of starting labour to ensure delivery of fetus.

Expectant management carries a risk of infection when induction is delayed for more than $24 \mathrm{hrs}$, while there is risk of failed induction and operative delivery if induction is attempted too $\mathrm{soon}^{8,9}$. Several recent studies on term with PROM have shown favourable results for induction of labour with prostaglandins $^{2,3,10,11}$.

Misoprostol (cytotec, Searle) is a prostaglandin E1 analogue, acts by increasing ripening at term by altering the glycosaminoglycan content of the cervix. It is inexpensive, easily stored at room temperature and has few systemic side effects. It is rapidly absorbed orally and vaginally. Misoprostol has been widely used 
for obstetric and gynecological indications such as induction of labour and PPH. This study was conducted due to regular turn over of patients with PROM at term in our unit. There is ongoing controversy while making the decision about their mode of managementi.e active vs. expectant.

\section{STUDY DESIGN}

It was Quasi experimental study.

\section{MATERIAL AND METHODS}

The study was undertaken among women with term pregnancies (37-42 wks) with PROM, gravida 2-5 and with cephalic alive fetuses. Patients who were not included were those who were already in labour, with chorioamnionitis, fetal compromise, previous caesarean section or uterine surgery, multiple pregnancies and high risk pregnancies like diabetes and pregnancy induced hypertension. Sixty patients of PROM at term were registered. 30 were placed in misoprostol (Group-A) and induced with $25 \mu \mathrm{g}$ vaginal misoprostol at 6 hourly interval upto max of four doses, 30 patients were placed in expectant group (Group-B), who were managed expectantly for 24hours followed by induction with intravenous oxytocin if labour did not start in 24 hours. The collected information was entered into SPSS version
11 and analyzed.

\section{RESULTS}

A total of sixty patients of PROM between 37 to 42 weeks of gestation were included in the study, who were divided into two equal groups of 30 each.

The patients included in the study were 20-35 years of age. The greatest number of patients in both groups were found $>40$ weeks of gestation (i.e. $15(50 \%)$ in group A and $18(60 \%)$ in group B. Highest number of patients in both the groups were 2 nd gravidas.

Regarding duration labour, group A had significantly shorter duration of labour as compared to group $B$.

In group A, 19 patients (63.3\%) had spontaneous vaginal delivery, 5 (16.6\%) had instrumental delivery and $6(20 \%)$ underwent caesarean section. While in group B, 17 patients $(56.7 \%)$ delivered vaginally, 4 (13.3\%) had instrumental delivery and $9(30 \%)$ delivered by caesarean section. Caesarean section rates differed by $10 \%$ between two groups.

In group $A, 18$ patients were having babies with APGAR score 10 at $5 \mathrm{~min}$. while in group $B, 19$ patients were having babies with APGAR score 10 at 5 min.

\begin{tabular}{|c|c|c|c|c|c|}
\hline & & \multicolumn{2}{|c|}{ PGE (Group A) } & \multicolumn{2}{|c|}{ Expectant (Group B) } \\
\hline & & No & $\%$ & No & $\%$ \\
\hline \multirow{3}{*}{ Parity } & G-2 & 12 & 40 & 18 & 60 \\
\hline & G-3 & 10 & 33.3 & 7 & 23.3 \\
\hline & G-4 & 8 & 26.7 & 5 & 16.7 \\
\hline \multirow{2}{*}{$\begin{array}{l}\text { Gestational age } \\
\text { (Weeks) }\end{array}$} & $37-40$ & 15 & 50 & 12 & 40 \\
\hline & $>40$ & 15 & 50 & 18 & 60 \\
\hline
\end{tabular}




\begin{tabular}{|c|c|c|c|c|}
\hline \multirow{2}{*}{ Duration of labour (hours) } & \multicolumn{2}{|c|}{ PGE (Group A) } & \multicolumn{2}{|c|}{ Expectant (Group B) } \\
\hline & No & $\%$ & No & $\%$ \\
\hline With in $12 \mathrm{hrs}$ & 10 & 33.3 & 4 & 13.3 \\
\hline With in $18 \mathrm{hrs}$ & 20 & 66.7 & 10 & 33.3 \\
\hline With in $24 \mathrm{hrs}$ & 22 & 73.3 & 13 & 43.3 \\
\hline With in 36 hrs & 28 & 93.3 & 23 & 76.7 \\
\hline With in $48 \mathrm{hrs}$ & 29 & 96.7 & 27 & 90 \\
\hline Meant \pm SD & \multicolumn{2}{|c|}{$18.9 \pm 11.0$} & \multicolumn{2}{|c|}{$27.5 \pm 14.8$} \\
\hline
\end{tabular}

\begin{tabular}{|c|c|c|c|c|}
\hline \multirow{2}{*}{ Mode of Delivery } & \multicolumn{2}{|c|}{ PGE (Group A) } & \multicolumn{2}{c|}{ Expectant (Group B) } \\
\cline { 2 - 5 } & No & No & 17 & 56.7 \\
\hline SVD & 19 & 63.3 & 4 & 13.3 \\
\hline Instrumental & 5 & 16.6 & 30 \\
\hline C/S & 6 & 100 & 30 & 100 \\
\hline Total & 30 & & \\
\end{tabular}

\begin{tabular}{|c|c|c|c|c|c|}
\hline \multirow{2}{*}{\multicolumn{2}{|c|}{ APGAR score at $5 \mathrm{~min}$}} & \multicolumn{2}{|c|}{ PGE (Group A) } & \multicolumn{2}{|c|}{ Expectant (Group B) } \\
\hline & & \multirow{2}{*}{$\begin{array}{l}\text { No } \\
18\end{array}$} & \multirow{2}{*}{$\begin{array}{c}\% \\
60\end{array}$} & \multirow{2}{*}{$\begin{array}{l}\text { No } \\
19\end{array}$} & \multirow{2}{*}{$\begin{array}{c}\% \\
63.3\end{array}$} \\
\hline & 10 & & & & \\
\hline & 09 & 10 & 33.3 & 8 & 26.3 \\
\hline & 08 & 1 & 3.33 & 1 & 3.33 \\
\hline & 7 or & 1 & 3.33 & 2 & 6.67 \\
\hline Mean + SD & & \multicolumn{2}{|c|}{$9.50+0.73$} & \multicolumn{2}{|c|}{$9.47+0.86$} \\
\hline
\end{tabular}

\section{DISCUSSION}

The time from PROM until delivery (total duration of labour) was significantly shorter in the group randomized to immediate induction using misoprostol. In the literature, these findings are in agreement with controlled studies in which prostaglandin E2 administered vaginally was compared with expectant management for a period of 24 hours followed by induction of labour in cases of term PROM. Caesarean section rates were $20 \%$ and $30.7 \%(P=0.22)$, respectively, in the group that received misoprostol compared with the expectant management group, a non-significant difference. The group that received misoprostol had better results with respect to the rate of vaginal delivery as a difference of $10 \%$ in these rates cannot be considered negligible. The lack of significant difference in caesarean delivery rates could easily be result of a type II error and, therefore, it is possible that a compilation of these data in a future meta-analysis may achieve a sufficient number of cases to show that this difference is also statistically significant. In view of the concern 
regarding the indexes that reflect condition at birth, which are also related to the process of labour induction and delivery, and the risk of infection in cases of PROM, one of the objectives of this study was to evaluate neonatal results from both groups and these proved to be highly satisfactory. These results are in agreement with the current literature ${ }^{9,10,11}$ which perinatal outcomes are normal even in cases of expectant management for long periods, provided care is taken to avoid digital vaginal examination and that there is no prior clinical evidence of chorioamnionitis. With regard to maternal postpartum follow up, results were also extremely favorable in both groups with minimal rates of puerperal infection, requirement for antibiotic therapy and other complications, and there was not significant difference between the two groups. These results are also in agreement with the literature ${ }^{9,10,11}$. However, it should be remembered that the sample size estimate was not performed taking these factors into account and therefore the study does not have enough power to definitely conclude on these aspects. The time interval between PROM and delivery, (i.e total duration of labour) which was both significantly shorter in the group that received misoprostol, as well as the reduction in caesarean section rates in the group randomized to immediate induction, show the induction with misoprostol, both in terms of cost and with regard to benefits, is a safe, inexpensive and efficient option for the induction of labour in cases of term PROM. On the other hand, a further option of choice in the management of cases of term PROM would be to present the options to the women so that she, herself could choose which among the possible management options, she would prefer. As said before under this point of view, both options would seem attractive to women. Therefore, although misoprostol showed to be a more effective option for term PROM, this situation could perhaps be adequately addressed using either vaginal misoprostol or a relatively short period of expectancy (24 hours) followed by induction of labour with oxytocin only if really necessary, considering that the majority of women experience the onset of labour within this period. In practical and clinical terms, the second option would only imply in a relatively longer period of labour and maternal hospital stay, but perhaps with a slightly higher chance of caesarean section.

\section{CONCLUSION}

Labour induction in patients with PROM at term shortens the duration of labour, maternal hospitalization and workload of patients in labour room where patient turnover is high.

\section{Copyright@C 20 Apr, 2013.}

\section{REFERENCES}

1. Alexander JM, Cox SM. Clinical course of premature rupture of membranes. Semen Perinatol 1999; 20:309-74.

2. Tan BP, Hannah ME. Prostaglandins versus oxytocin for prelabour rupture of membranes at term (Cochrance review). Cochrance Database Sys Rev 2000; 2: Cd000158.

3. Krupa FG, Cecatti JG, Surita FGC, Milanez HMG, Parpinelli MA. Misoprostol versus expectant management in premature rupture of membranes at term. BJOG 2005; 112: 1284-90.

4. Najibullah TW. Maternal and fetal outcome of prelabour rupture of membranes at term, expectant management. Ann KE Med Coll 2004; 10:141-3.

5. Walkinshaw SA. Preterm labour and delivery of the preterm infant. In: Chamberlain G, Street P, editors. Turnbull obstetrics. 3rd ed. London: Harcourt Publishers 2001; 493-520.

6. Svigos M, James DK, Weiner CP, Steer PJ, Gonik B, editors. High risk pregnancy management options. 3rd ed. New Delhi: Elsevier 2006; 1321-33.

7. Tenore JL. Methods for cervical ripening and induction of labour. Am Fam Physician 2003; 67:21238.

8. Ngai SW, Chan YM, Lam SW, Lao TT. Labour characteristics and uterine activity; misoprostol 
compared with oxytocin in women at term with prelabour rupture of membranes. BJOG 2000; 107:222-7.

9. Hanna ME, Hodnett ED, Willan A. Prelabour rupture of the membranes at term: expectant management at home or in hospital? The term PROM Study Group. Obstet Gynecol 2000; 96:533-8.

10. Tan BP, Hannah ME. Prostaglandins versus oxyotcin for prelabour rupture of membranes at or near term (Cochrane Review) Cochrance Database Sys 2000; 2: Cd000159.

11. Chaudhri R, Naheed K. A. Comparison of active and expectant management of prelabour spontaneous rupture of membranes (PROM) at and near term. Pak Armed Forces Med J 2002; 52; 38-46.

\section{AUTHOR(S):}

1. DR. BUSHA KHAN

Senior Registrar, Unit-I

Obstetrics \& Gynaecology Department,

Sheikh Zayed Medical College/Hospital, Rahim Yar Khan.

2. DR. NUZHAT RASHEED

3. DR. BUSHRA MUKHTAR

\section{Correspondence Address:}

Dr. Bushra Khan

Senior Registrar, Ward No. 17,

Nishtar Hospital and Medical College, Multan.

manuchehera@yahoo.com

\section{PREVIOUS RELATED STUDIES}

Misbah Kausar Javaid, Samia Hassan, Tayyaba Tahira. MANAGEMENT PRELABOUR RUPTURE OF THE MEMBRANES AT TERM; INDUCTION OF LABOUR COMPARED WITHEXPECTANT (Original) Prof Med Jour 15(2) 216-219Apr, May, Jun 2008.

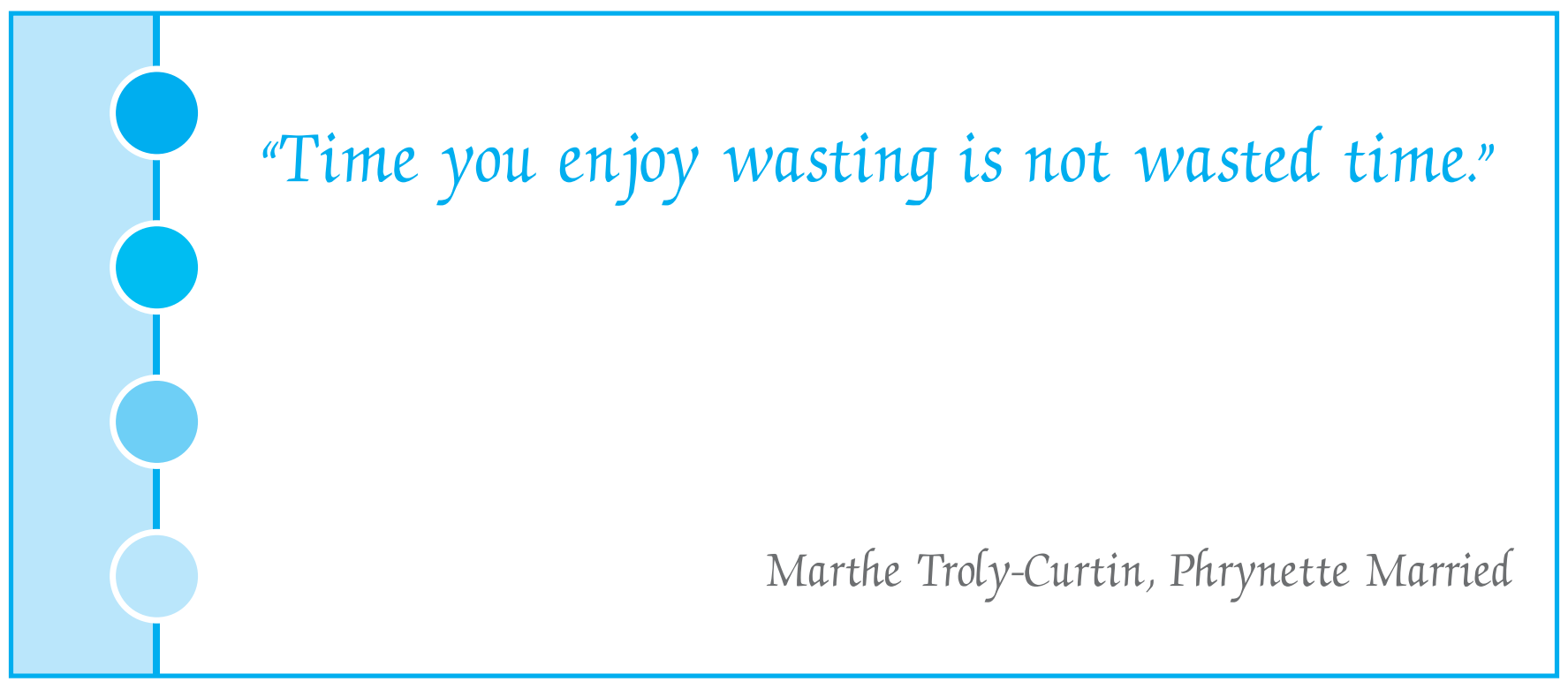

